\title{
South Africa's Nuclear Forensics Response Plan Step 1 - in Support of Nuclear Security Investigations
}

\author{
Phuti Reuben Mogafe ${ }^{1 *}$, Banyana Kokwane ${ }^{1}$, Precious Tshidada ${ }^{1}$, AmosL Matshiga ${ }^{1}$ and JJHancke ${ }^{1}$ \\ Nuclear Obligations Management Services Department (NOMS Department), South African Nuclear Energy Corporation (NECSA), \\ Pelindaba 0001, South Africa
}

\begin{abstract}
In South Africa, the nuclear forensics approach and its functions hosted and managed by Necsa, in support of any nuclear security investigations, start from the incident scene when the nuclear or radioactive material (that is out of regulatory control) is being handled and handed over to Necsa Emergency Control Centre by the South African law enforcement agencies in the presence of NOMS Department official. The main objective of this approach is to increase the credibility status of the chain of custody on the handling of the material during incident (crime) scene management process (for both nuclear forensics and traditional forensic evidence collection) and its transportation from the scene to the suitable storage facility at Necsa. Aspects to be looked into during the response process include interactions between law enforcement agencies, Necsa relevant departments and the National Nuclear Regulator of South Africa. This paper focuses on the entire whole response process and associated prior arrangements, in order to show and provide a set of requirements attached to the material , the scope of critical relevant technical and law enforcement information that to be acquired by all parties involving and participating in the nuclear/radiological incident or event response process before the material is authorized for storage at a suitably qualified Necsa's nuclear forensics, which is dedicated storage facility on Pelindaba site.
\end{abstract}

Key words: Response plan, nuclear incidents.

\section{Introduction}

South Africa abandoned its nuclear weapons program, joined the treaty on the NPT (Non proliferation treaty) of nuclear weapons as a non-nuclear weapon state in 1991 [1], and allowed international inspections of its former nuclear weapons program. Since abandoning its nuclear weapons program, South Africa has emerged as a champion of both global nuclear non-proliferation and equal access to peaceful nuclear energy. However, South Africa's remaining dual-use nuclear capabilities have made it both a possible exporter of nuclear technology and know-how, and a target for state and non-state actors seeking assistance for nuclear materials handling, protection and storage facilities.

South Africa is a producer, possessor, and exporter

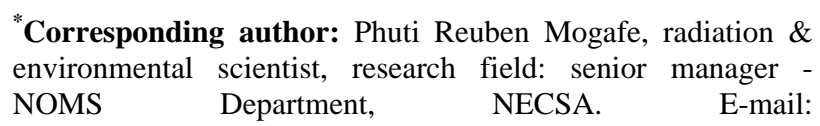
reuben.mogafe@necsa.co.za. of nuclear materials and technologies for peaceful purposes. Radioactive/nuclear materials find uses in various sectors of this country's economy and these include the mining industry, health sector, research and development and energy sector. Escom, the South African electricity utility, operates two nuclear power reactor units, that is Koeberg 1 and 2 respectively, which together produce 1,800 MWe. Necsa operates the $20 \mathrm{MWt}$ Safari-1 reactor at its Pelindaba nuclear research centre. Safari-1 is the main supplier of medical radioisotopes in Africa and can supply up to $25 \%$ of the world's molybdenum-99 needs. By 2009, the reactor was converted from using HEU (Highly enriched uranium) to LEU (Low enriched uranium) fuel [2], and conversion of the targets used for radioisotope production from HEU to LEU was achieved in 2010.

Uranium production in South Africa has generally been a by-product of gold or copper mining. In 1951, a company was formed to exploit the uranium-rich 
slurries from gold mining and in 1967 this function was taken over by Nuclear Fuels Corporation of South Africa (Nufcor), which in 1998 became a subsidiary of AngloGold Ltd. It produces over $600 \mathrm{t}$ of $\mathrm{U}_{3} \mathrm{O}_{8}$ per year from uranium slurriestruked in from various gold mines and Phalaborwa copper mine

Major security concerns for radioactive materials usage include theft of radioactive sources, illicit trafficking in nuclear and radioactive material, etc. Nuclear incidents (nuclear related illicit trafficking) have been defined as incidents which involve unauthorized acquisition, provision, possession, use, transfer or disposal of nuclear materials with or without crossing international borders including thwarted and unsuccessful events [3]. Responding plan to these incidents involves many organizations, (of highly specialized law-enforcement and technical expertise) which may include agencies such as police (criminal investigations), intelligence unit, prosecuting authorities, national nuclear forensics laboratories, nuclear regulatory authorities, etc. As a consequence, a comprehensive response plan is required, clearly describing the responsibilities of the authorities involved and the roles of the individual actors in the events. The response plan to handle the events of illicit trafficking of nuclear material is discussed in this paper. The IAEA suggests a generic response plan [4] and this were used as a guide.

It should be noted that the safety and security of these materials is guaranteed through an effective national regulatory control infrastructure. However, nuclear or radioactive materials that is out of regulatory control form the integral part of the nuclear terrorism or crime threat across the country and also in other parts of the Southern African region.

It is a customary to divide nuclear forensics in the form of "pre-detonation" and "post-deponation" disciplines" [5]. Until now the main focus of the Nuclear Forensics Department has been on the "predetonation" aspects of nuclear forensics. The experience up until now, as well as the international standing of South Africa, has made this the sensible approach. "Postdetonation" forensic analysis may be performed by existing laboratories at Necsa.

\section{National Competences, Statutory and Regulatory Framework}

Although the prevention of nuclear and radiological terrorism is a global issue or initiative, the establishment of an efficient and well defined system for combating illicit nuclear material is understood to be a national responsibility and the legal framework must exist to combat this threat. In this regard, the Republic of South Africa has an effective nuclear regulatory framework which is derived from a set of well detailed comprehensive legislation which include Nuclear Energy Policy of 2008, Nuclear Energy Act, 1999 (Act 46 of 1999) and the National Nuclear Regulatory Act, 1999 (Act 47 of 1999). Other related legislation includes Non-Proliferation of Weapons of Mass Destruction Act, 1993 (Act 87 of 1993); National Radioactive Waste Disposal Institute Act, 2008 ( Act 53 of 2008); the Hazardous Substances Act, 1973 (Act 15 of 1973); National Strategic Intelligence Act, 1994 (Act 39 of 1994); National Key Points Act, 1980 (Act 102 of 1980); Disaster Management Act, 2002, (Act 57 of 2002) and the Protection of Constitutional Democracy Against.

\section{Nuclear Forensics in Support of National Nuclear Security}

Ministerial roles and responsibilities are integrated into a national nuclear security response plan, for prevention and detection of and response to theft, sabotage, unauthorized access, illegal transfer or other malicious acts involving nuclear material, other radioactive substances or their associated facilities. Role players include department of energy as custodian of the deployed Nuclear Security Plan, National Nuclear Regulator, Department of Health, State Security Agency, SAPS (South African Police Service) and Justice, Defence, IAEA Guidelines, etc. In addition, 
nuclear forensics is now one component in a support of on-going National Nuclear Security Investigations. Nuclear forensic science (used in this paper as Nuclear Forensics) aims at providing clues on nuclear or other radioactive material which are out of regulatory controls or involved in illicit trafficking incidents. Credible nuclear forensics can only be achieved if all evidence and case history are preserved and made available for data interpretation and source attribution. Hence, in the context of the South African nuclear security events or incidents investigations, nuclear forensics investigations have to start at the "crime scene”.

\section{Nuclear Forensics Capacity Building}

It is undoubtedly, a point and also worth mentioning that today nuclear forensics approach and its functions across the globe are increasingly become important tools in the fight against the illicit trafficking of nuclear and radiological materials in the area of nuclear security and safeguards investigations. The publication by Moody, Hutcheon and Grant [6] is a valuable source of general information. The South African government has committed itself to develop the country's nuclear forensics capability in order to support the prevention, investigations and response to nuclear security events. Nuclear forensics is established to be a key technical capability of the national response plan to address nuclear and radioactive material out of regulatory control. To achieve this, South Africa is in a process of final being the establishment of national nuclear forensics capabilities which include national nuclear forensics laboratory to analyze the evidence contaminated with radioactive material and establishing the procedures to respond to nuclear security events including those for the collection and transportation of evidence linked to nuclear or radioactive material. The South African Nuclear Energy Corporation Limited (Necsa) is authorized to fulfil the commitments of nuclear forensics since it acts as the national authority (national key point in nuclear) and contact point for the following IAEA conventions: Convention on early notification of a nuclear accident; Convention on assistance in the case of a nuclear accident or radiological emergency.

Responding plan to these incidents involves many organizations (highly specialized law-enforcement and technicasl expertise), which may include agencies such as police (criminal investigations), intelligence unit, prosecuting authorities, national nuclear forensics laboratories, nuclear regulatory authorities, etc. Hence the plan should be able to describe the roles and responsibilities of the relevant national agencies and authorities involved in response situation to these incidents. Therefore in order to be effective, the response plan to a call must be well coordinated to preserve the evidence from contamination [7] which should also provide guidance for responding to this kind of incidents when nuclear forensics investigations are required.

Nuclear incidents (nuclear related illicit trafficking) have been defined as incidents which involve unauthorized acquisition, provision, possession, use, transfer or disposal of nuclear materials with or without crossing international borders including thwarted and unsuccessful events [3]. This paper focuses on the entire response process and associated prior arrangements in order to show and provide a set of requirements attached to the material. The scope of critical and law enforcement information to be acquired by all parties involved and participating in the nuclear or radiological incident or event should be clear to all parties to avoid confusion or conflicting ideas as these may also pose a contributing factor and some implication on the credibility of overall chain of custody pertaining to the event itself.

\subsection{Response}

The response team is led by any law enforcement agency (Fig. 1). In case of a suspected nuclear/radiological incident, or there is an object found 


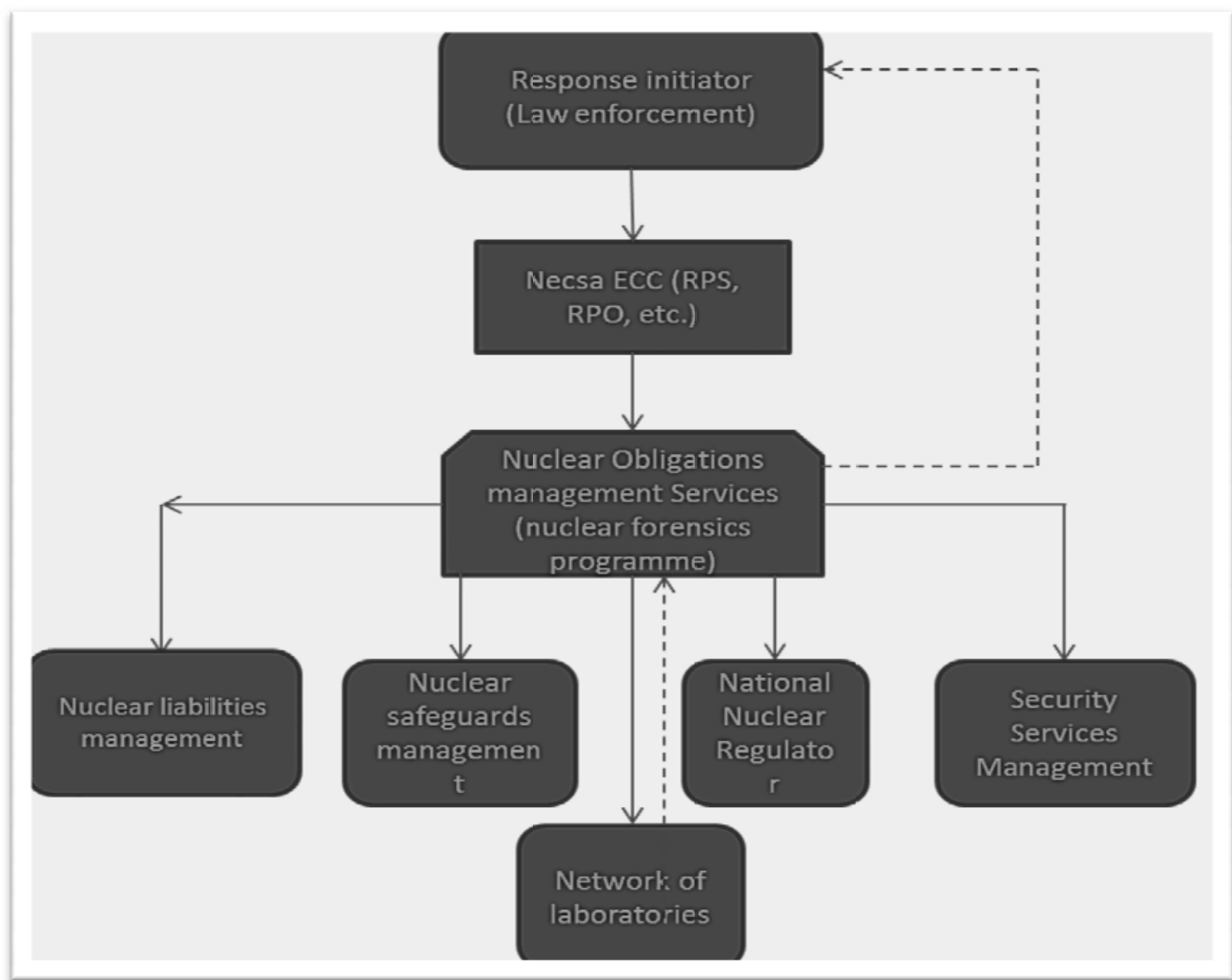

Fig. 1 The NOMS response hierarchical communication model structure to a nuclear or radioactive event in South Africa. Solid lines mean event call \& communication, dotted lines mean official results \& reports communication.

or seized which is assumed to be radioactive/nuclear material or has been contaminated by such materials the police or any law enforcement involved, after conducting initial assessment whose results will determine whether a nuclear event has occurred or not, must prevent individuals from accessing the area or object (crime scene). The response initiator has the detective administrative action powers against crimes concerning nuclear and radioactive materials that are out of regulatory control.

On information or suspicion of it being a nuclear related incident the crime investigating unit (in this case being the SAPS Bomb Disposal Explosive Section) will report the incident to the Necsa ECC (Emergency Control Centre), which is in principle the first contact point on all incidents involving illicit radioactive and nuclear materials brought into Necsa site. Necsa ECC representatives are on a call $24 \mathrm{~h}$ per day and are well trained and dedicated to technically assess the incident using dedicated tools to detect radiation levels, quantitative measures to a certain extent.

If the incident is confirmed to be a nuclear event ECC assumes the responsibility of attending or responding to the incident to ensure that any radiation protection measures are in place to control and protect the public and the response teams. They will also initiate the process of sending relevant experts to the scene for operations and collection of the material. In addition to notifying its own responsible units, ECC will notify NOMS (Nuclear Obligations Management Services) department (In the event that the material is serving as criminal evidence) before initiating the process of sending relevant RPO/RPS (Radiation Protection Officers/Protection Specialists) to the scene for operations and collections. Following this notification NOMS Department then informs the 
following departments: Security Services Department of Necsa (in the case in which the material is brought into Necsa site); The NNR (National Nuclear Regulator) through Safety \& Licensing Department of Necsa; The South African Nuclear Safeguards; Nuclear Liabilities Management Department of Necsa; National Intelligence Agency through Necsa Security Services Department (threat assessment ).

The NOMS Department of Necsa is responsible for, amongst other nuclear forensics roles, the evidence collection and management, chain of custody management, nuclear material sampling, required analyses, results interpretation, full report preparation and submit reports to the SAPS (South African Police Services), building the national nuclear forensics database (library), submit information to Nuclear Safeguards Department for reporting to the IAEA (on the IAEA's ITDB).

For consistent and credible chain of custody information on the evidence of the event, the Necsa ECC and NOMS Department representatives are required to attend or react to a police response call out to ensure the proper handling and collection of the sample/material from the environment to the radiological controlled areas (facilities) at Necsa.

\subsection{What Happens at the Nuclear Event Scene}

At the scene, all conventional safety measures, radiological protection measures and proper handling of the materials to preserve evidence credibility for both nuclear forensics and traditional forensic investigations are critical steps to overrun the event scene management. As a result the following steps will be followed to ensure that compliance to the above critical steps is met:

Collection of traditional forensic evidence and evidence contaminated with radioactive material will be performed in a manner consistent with radiological safety practices.

If the experts RPO (Radiation Protection Officer) and RPS (Radiation protection specialist) determine that seized material is radioactive, then a preliminary inventory will be taken. A Pro-forma form will be issued to all officials who will be attending to the response call-out and collect the material, determining the quantity of the material, and an inspection made of the packaging, and the materials collected. Officials who will attend to the scene from Necsa include ECC (RPO or RPS), NOMS Department, NLM (Nuclear Liabilities Management). They will fill in the form and sign it for receiving the material from the law enforcement agencies. The form will record material information such as the type of material and its dose rates, visual inspection information (package type, contents color, material form: powder, liquid, solid etc.).

In the event that the material is serving as criminal evidence, the regulations governing the handling and recording of objects seized in criminal proceedings will be observed when taking samples of the material, as well as during the testing and storing of such.

The material will then be transported in a specialized transport vehicle to Necsa storage facility (currently temporary storage facility of NLM Department or other suitable facility within Necsa) designated for this purpose by NOMS Department in consultation with NLM Department or other responsible Department.

\subsection{Handling of Evidence Contaminated with Radioactive Material on Necsa Site}

Upon receiving the illicit nuclear or radioactive material on Necsa site, NOMS assumes interim ownership and control over the material for the sake of internal Necsa chain of custody credibility and also coordinates the process of attaining all the necessary and relevant information about the material. It is the responsibility of NOMS Department to make the relavant departments aware that the material is on site and subsequently provides a brief description of the activities to be performed by each department.The NOMS performs screening measurements NDA (Non destructive analysis) or Assay NDA on every material 
in question before submitting samples for the DA in the laboratory. The report, based on the NDA (screening) results with a short description on the intepretation of the results, is then sent over to relevant Law Enforcement Agencies, National Nuclear Regulator, Nuclear Safeguards and lastly most importantly populate our national Nuclear forensics database with the data/information.

\subsection{Security Services}

The working principle for the nuclear security event material transported to Necsa for storage and nuclear forensic analysis is that, at the Necsa site entry point (gate), the security services department official shall aknowledge by signing the pro-forma form that the material has been taken into Necsa. And also if required, assist with the escort services in cases where SAPS officials are transporting the material on site. Following all relevant officials signatures, NOMS official will accept the material together with Pro-forma to the storage facility and sign for the interim ownership and control of the material.

\subsection{Nuclear Safeguards Management Department}

The Nuclear Safeguards Department will be informed of the material as usual and Safeguards Officials will perform the following activities for their records:

Preliminary NDA measurements in order to characterize the material

Record the material information its system for control and reporting to IAEA. Although Safeguards Department is primarily not resposnible and directly involved in the investigaations of the nuclear security events, all findings related to the events are ussually submitted to them for updating the IAEA.

\subsection{Nuclear Liabilities Management (NLM)}

This is the main Necsa' Storage Facilities Department. Due to Necsa not having a special storage facility specifically for the nuclear forensics material or samples, the NLM Department licensed storage facilities are used temporarly as interim storage facilities to keep some nuclear security events material.Therefore since the storage facility is falling under Necsa's NLM Department then the facility manager or any assignee shall sign the Pro-Forma form indicating that the materail has been stored in that facillity under the name of MOMS department.

\section{International Cooperation in Combating ILLICIT Trafficking}

For South Africa to be able to develop credible and advance capabilities in nuclear forensics there should be cooperation and collaboration initiatives. As a key nuclear R \& D Organization in South Africa, Necsa and the USA national laboratories LLNL (Lawrence liver more national laboratory) and LANL (Los Alamos national laboratory) have entered into and signed a MOU (Memorandum of understanding) in 2011 for collaboration (work together) in the field of nuclear forensics. The collaboration aims mainly for the establishment of nuclear forensics capabilities in South Africa which include the development of a national nuclear forensics laboratory and the national nuclear forensics database (library).

In this regard, a national nuclear forensics laboratory (Fig. 2), which will include a nuclear security response training component, is at a final stage of construction and thereby entering the commissioning stage. The laboratory and the nuclear forensics associated training achievements are the result of the existing collaboration between Necsa (The South Africa's Nuclear Energy Corporation) and the LLNL-LANL of the US DOE (Department of Energy). Several training phases have already been undertaken, such as nuclear forensics analysis training course in the US at LLNL in 2012.

South African representatives participated in numerous training courses, workshops, meetings and conferences that were funded and organized by US government and the IAEA. 


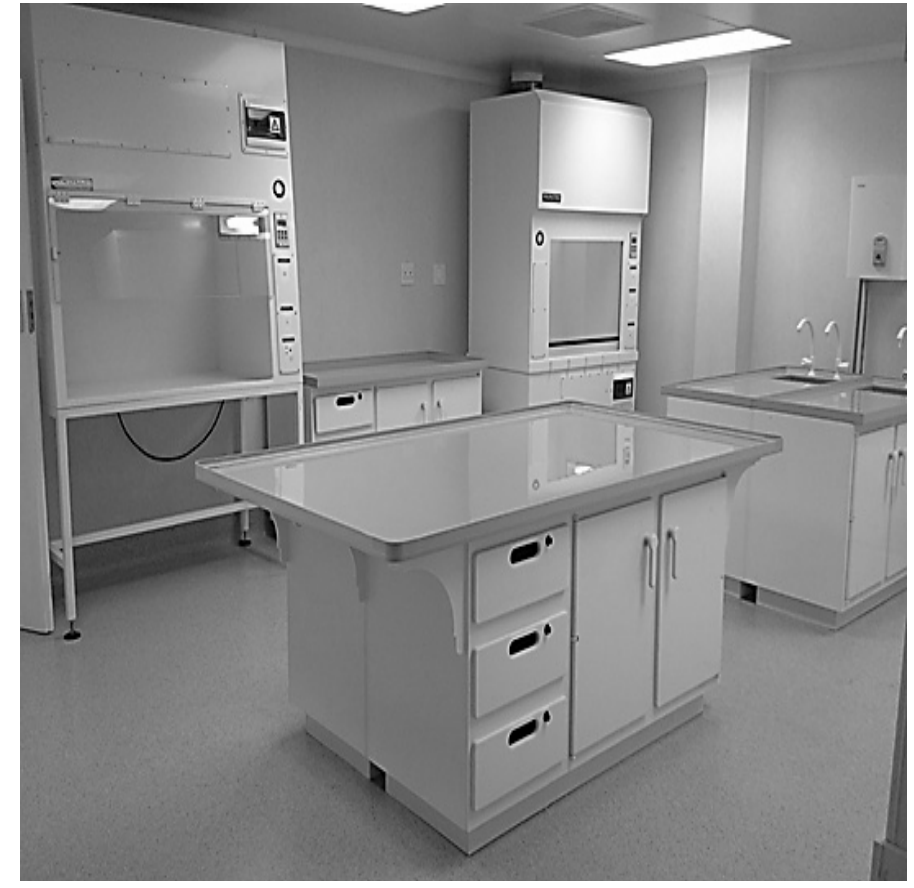

Fig. 2 Part of Necsa's new nuclear forensics laboratory under construction.

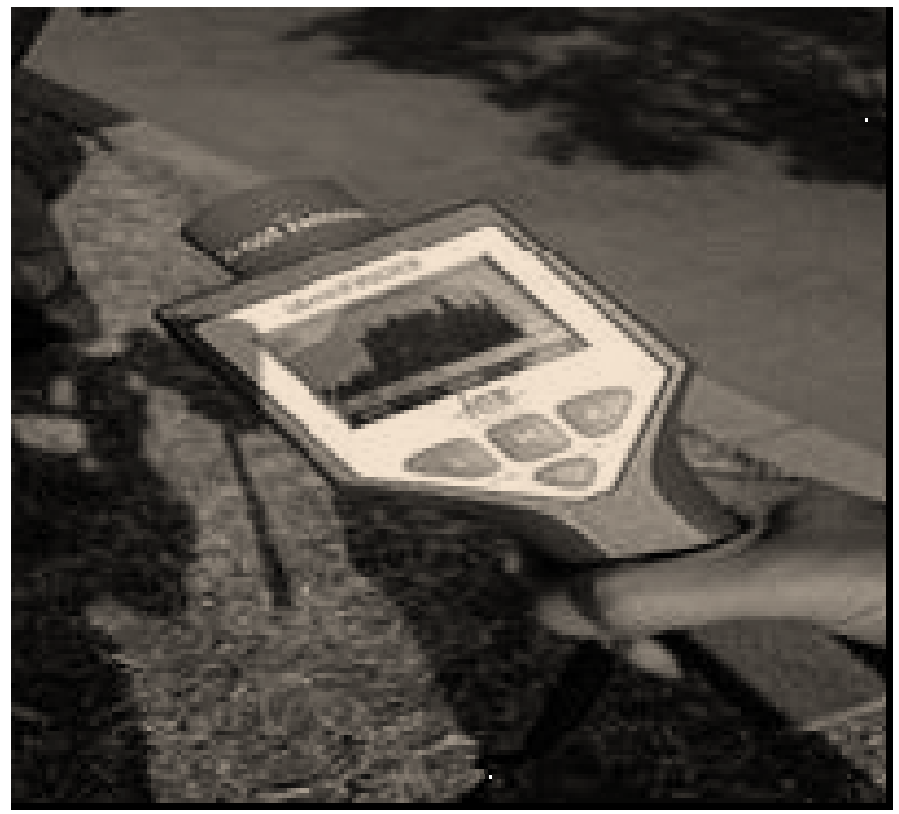

Fig. 3 Some of the equipment donated by IAEA to South Africa in 2010.

South Africa is a Participating State in the IAEA's ITDB (Incident and illicit trafficking database).

As a reflection of good international relations and co-operation South Africa has, the IAEA and the US Department of Energy donated the nuclear security equipment's (Fig. 3) that were utilized during major public events from 2010-2013 on the effort of strengthening the nuclear security system in the country.

\section{Experience on Illicit Trafficking of Nuclear and or Radioactive Material}

Very few illicit trafficking incidents reported in South Africa were associated with criminal cases under 
SAPS custody. The following are typical incidents handled by NOMS-NFP for nuclear forensic analysis.

On the 14th October 2011 the material was brought to the Necsa site by the police official. This was a $5 \mathrm{~L}$ bottle that contained yellow sediment and a clear supernatant liquid. The bottle was labelled as uranium trioxide. Analysis confirmed it to be uranium material with 11.52 g U-235.

On Tuesday 10 Jan 2012 two containers containing uranium were confiscated in Sandton area. These weighed about $1.2 \mathrm{~kg}$ and $0.5 \mathrm{~kg}$ respectively. On Friday 13 Jan 2012 one container containing uranium was confiscated again in Sandton area and delivered to Necsa for NFP, this weighed about $0.8 \mathrm{~kg}$.

On 14 November 2013 South African Police Services arrested two men on a suspicion of possessing uranium and some tablets which were stored (packaged) in a plastic bag. The package was sent to Necsa for analysis. On receiving the material, NDA screening has indicated that the material consisted of depleted uranium with the radiation dose of approximately 0.58 $\mu \mathrm{Sv}$.

Prosecution was done based on the Regulations in terms of the Nuclear Energy Act [8], which, declares the unauthorized possession of these materials illegal.

\section{Conclusions}

South Africa continues to enhance measures for strengthening the national and regional nuclear security regimes in the country and nearby countries by developing and executing the national nuclear forensics capabilities. All these capabilities are grouped together under a National Nuclear Forensics Programme within the NOMS Department of Necsa (NOMS-NFP). The Nuclear Forensics Laboratory and the National Nuclear Forensics Library (Database) are the first two technical capabilities to be developed through our cooperation and collaboration with the
IAEA and the US DOE National Nuclear Security Agency (NNSA) which includes LLNL and LANL. The IAEA together with the US Department of State and the US DOE's NNSA (LLNL and LANL) have been and are still playing a very critical role in supporting our efforts towards establishing the national nuclear forensics capabilities and the associated international participation in nuclear forensics training, workshops, meetings and conferences which form a significant part of international cooperation in general.

\section{References}

[1] "Nuclear Reactor Uses Only Low Enriched Uranium (LEU) for the First Time”, South African Nuclear Energy Corporation media release. 29, June , 2009.

[2] National Nuclear Regulatory Act, 1999 (Act 47 of 1999).

[3] International Energy Agency. "IAEA Incident and Trafficking Database (ITDB): Incidents of Nuclear and other Radioactive Material out of Regulatory Control, 2014 Fact Sheet.” http://tutorials.nti.org/nuclear-and-radiological-security/il licit-trafficking/\#sthash.rzT6EbS4.dpuf.

[4] "Non-Proliferation of Nuclear Weapons and Nuclear Security.” IAEA Safeguards Agreements and Additional Protocols. May 2005

[5] "Nuclear forensics support provides some guidelines." IAEA Nuclear security Series No2 (Technical Guidance).

[6] "Nuclear Forensics Guideline Response Process for Collection of Law Enforcement Suspected and Unregulated Nuclear/Radioactive Materials \& Some Sources to be Handed-Over to Necsa for Storage and Nuclear Forensics.” NOMS-OH-PRC-0001 (Revision 1.0).

[7] "Nuclear Forensics." GAO-09-527R Washington DC, April 302009

[8] Nuclear Energy Act (Act 46 of 1999) Regulations published in Government Gazette 31954, 27 February 2009.

[9] Moody, K. J., Hutcheon, I. D. and Grant, P. M. 2005. Nuclear Forensic Analysis. CRC Press: Boca Raton, Fla., vi-vii.

[10] "Generic Procedures for the Assessment and Response during a Radiological Emergency.” IAEA-TECDOC-1162. 